\section{Commentary: Hypertrophic cardiomyopathy and the mitral valve - the debate continues}

\author{
Alison F. Ward, MD, and Richard Lee, MD, JD, MBA
}

In this edition of the Journal, Dearani and colleagues ${ }^{1}$ examine whether mitral valve (MV) leaflet length affects outcomes in patients with hypertrophic cardiomyopathy (HCM). In this retrospective study, MV leaflet lengths and coaptation length were measured by intraoperative transesophageal echocardiography (TEE) in 564 patients with HCM undergoing septal myectomy. The primary endpoint was relief of the left ventricular outflow tract (LVOT) gradient following myectomy, and secondary endpoints were reduction in the degree of mitral regurgitation (MR) and systolic anterior motion (SAM). Extended septal myectomy was performed in $74.5 \%$ of the patients, and MV procedures were performed only when intrinsic MV disease was present. None of the leaflet measurements were associated with postoperative resting LVOT gradient, magnitude of gradient relief, and preoperative or postoperative MR grade. However, there was a positive relationship between the 3 leaflet measurements and postoperative SAM, but the association between greater anterior leaflet (AL) length and postoperative SAM was not statistically significant.

This Mayo Clinic group has demonstrated excellent surgical results in this large group of HCM patients with a mortality rate of $<1 \%$, average postoperative LVOT gradient of $\leq 10 \mathrm{mmHg}$, and VSD rate of $<1 \%$. As the authors discuss, there are 2 opposing views on surgical management of HCM and the MV - isolated septal myectomy versus septal myectomy plus AL management of the MV. The authors

From the Division of Cardiothoracic Surgery, Department of Surgery, Medical College of Georgia, Augusta University, Augusta, Ga.

Disclosures: The authors reported no conflicts of interest.

The Journal policy requires editors and reviewers to disclose conflicts of interest and to decline handling or reviewing manuscripts for which they may have a conflict of interest. The editors and reviewers of this article have no conflicts of interest.

Received for publication Jan 11, 2021; revisions received Jan 11, 2021; accepted for publication Jan 12, 2021; available ahead of print Jan 20, 2021.

Address for reprints: Richard Lee, MD, JD, MBA, Division of Cardiothoracic Surgery, Department of Surgery, Medical College of Georgia, 1120 15th St, BA4300, Augusta, GA 30912 (E-mail: richardleemdmba@gmail.com or RICKLEE@augusta.edu).

J Thorac Cardiovasc Surg 2023;165:88-9

0022-5223/\$36.00

Copyright $₫ 2021$ Published by Elsevier Inc. on behalf of The American Association for Thoracic Surgery

https://doi.org/10.1016/j.jtcvs.2021.01.046

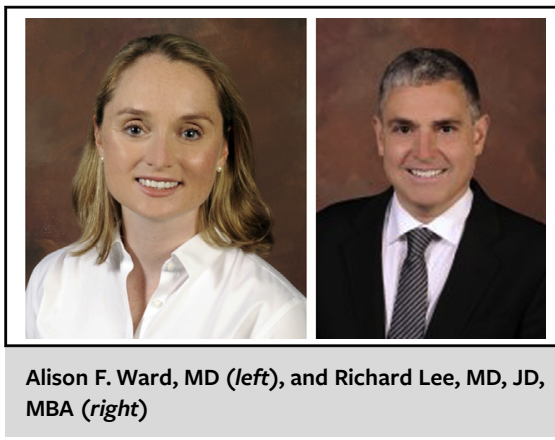

CENTRAL MESSAGE

In patients with hypertrophic cardiomyopathy undergoing septal myectomy, mitral anterior leaflet length does not affect left ventricular outflow tract gradient or mitral regurgitation (MR) on postoperative transesophageal echocardiography; long-term data on gradients and rates of MR warrant further study.

provide compelling data indicating that myectomy alone is adequate for addressing SAM and MR associated with $\mathrm{HCM}$, and that additional MV procedures are unnecessary unless intrinsic MV disease is present. ${ }^{1,2}$ In contrast, other $\mathrm{HCM}$ centers focus on the AL of the MV at the time of myectomy in selected HCM cases, such as those with a relatively thin septum. In 1992, McIntosh and colleagues ${ }^{3}$ published their technique of vertical plication of the anterior leaflet of the MV. Swistel and colleagues ${ }^{4-9}$ at New York University have described the "RPR" technique composed of resection, AL plication, and resection of abnormal papillary muscle attachments. Ferrazzi and colleagues ${ }^{10-12}$ in Monza, Italy have advocated division of the secondary chordae of the AL of the MV. Procedures to extend and stiffen the anterior leaflet have also been described. ${ }^{13,14}$ All of these groups have demonstrated success in reducing postoperative LVOT gradient, MR, and SAM.

Looking closer at the present data, the frequency of postoperative SAM and MR was not insignificant in these patients. postoperative SAM occurred in $65.6 \%$ of patients in the elongated $\mathrm{AL} \mathrm{MV}$ group versus $47.6 \%$ in the nonelongated AL MV group, a statistically significant difference. With this rate of SAM and a $>10 \%$ rate of 
moderate or greater MR in both groups of patients, one has to wonder whether the AL MV should be addressed. In addition, this retrospective study only looked at intraoperative TEE measurements and provided no long-term data on LVOT gradient, SAM, or MR.

Dearani and colleagues should be congratulated again on their extensive clinical experience with HCM surgery and these excellent results. We look forward to additional long-term data for the ongoing debate of myectomy versus myectomy plus AL MV surgery in HCM patients.

\section{References}

1. Carvalho JL, Schaff HV, Nishimura RA, Ommen SR, Geske JB, Lahr BD, et al. Is anterior mitral valve leaflet length important in outcome of septal myectomy for obstructive hypertrophic cardiomyopathy? J Thorac Cardiovasc Surg. 2023;165: 79-87.e1.

2. Hong JH, Schaff HV, Nishimura RA, Abel MD, Dearani JA, Li Z, et al. Mitral regurgitation in patients with hypertrophic obstructive cardiomyopathy: implications for concomitant valve procedures. J Am Coll Cardiol. 2016;68:1497-504.

3. McIntosh CL, Maron BJ, Cannon RO III, Klues HG. Initial results of combined anterior mitral leaflet plication and ventricular septal myotomy-myectomy for relief of left ventricular outflow tract obstruction in patients with hypertrophic cardiomyopathy. Circulation. 1992;86(5 Suppl):II60-7.

4. Balaram SK, Ross RE, Sherrid MV, Schwartz GS, Hillel Z, Winson G, et al. Role of mitral valve plication in the surgical management of hypertrophic cardiomyopathy. Ann Thorac Surg. 2012;94:1990-7; discussion 1997-8.

5. Balaram SK, Sherrid MV, Derose JJ Jr, Hillel Z, Winson G, Swistel DG. Beyond extended myectomy for hypertrophic cardiomyopathy: the resection-plicationrelease (RPR) repair. Ann Thorac Surg. 2005;80:217-23.
6. Balaram SK, Tyrie L, Sherrid MV, Afthinos J, Hillel Z, Winson G, et al. Resection-plication-release for hypertrophic cardiomyopathy: clinical and echocardiographic follow-up. Ann Thorac Surg. 2008;86:1539-44; discussion 1544-5.

7. Halpern DG, Swistel DG, Po JR, Joshi R, Winson G, Arabadjian M, et al. Echocardiography before and after resect-plicate-release surgical myectomy for obstructive hypertrophic cardiomyopathy. J Am Soc Echocardiogr. 2015;28: 1318-28.

8. Swistel DG, Balaram SK. Resection, plication, release-the RPR procedure for obstructive hypertrophic cardiomyopathy. Anadolu Kardiyol Derg. 2006;6(Suppl 2):31-6.

9. Swistel DG, Balaram SK. Surgical myectomy for hypertrophic cardiomyopathy in the 21st century, the evolution of the "RPR" repair: resection, plication, and release. Prog Cardiovasc Dis. 2012;54:498-502.

10. Binaco I, Spirito P, Poggio D, Casati V, Grillo M, Ferrazzi P. Transaortic mitral valve secondary chordal cutting in patients with obstructive hypertrophic cardiomyopathy and mild septal hypertrophy. Ann Cardiothorac Surg. 2017;6: 426-8.

11. Ferrazzi P, Spirito P, Iacovoni A, Calabrese A, Migliorati K, Simon C, et al Transaortic chordal cutting: mitral valve repair for obstructive hypertrophic cardiomyopathy with mild septal hypertrophy. J Am Coll Cardiol. 2015;66: 1687-96.

12. Urbano-Moral JA, Gutierrez-Garcia-Moreno L, Rodriguez-Palomares JF, Matabuena-Gomez-Limon J, Niella N, Maldonado G, et al. Structural abnormalities in hypertrophic cardiomyopathy beyond left ventricular hypertrophy by multimodality imaging evaluation. Echocardiography. 2019;36:1241-52.

13. van der Lee C, Kofflard MJM, van Herwerden LA, Vletter WB, ten Cate FJ. Sustained improvement after combined anterior mitral leaflet extension and myectomy in hypertrophic obstructive cardiomyopathy. Circulation. 2003;108: 2088-92.

14. Vriesendorp PA, Schinkel AFL, Soliman OII, Kofflard MJM, de Jong PL, van Herwerden LA, et al. Long-term benefit of myectomy and anterior mitral leaflet extension in obstructive hypertrophic cardiomyopathy. Am J Cardiol. 2015;115: $670-5$. 